\title{
Role of Metals Content in Spinach in Enhancing the Conductivity and Optical Band Gap of Chitosan Films
}

\author{
Irwana Nainggolan, ${ }^{1}$ Devi Shantini, ${ }^{1}$ Tulus Ikhsan Nasution, ${ }^{2}$ and Mohd Nazree Derman ${ }^{1}$ \\ ${ }^{1}$ School of Materials Engineering, Universiti Malaysia Perlis, 01000 Kangar, Perlis, Malaysia \\ ${ }^{2}$ Physics Department, Faculty of Mathematic and Natural Science, University of Sumatera Utara, Medan, \\ Sumatera Utara 20155, Indonesia
}

Correspondence should be addressed to Irwana Nainggolan; jasminee_24@yahoo.com

Received 19 October 2014; Accepted 26 February 2015

Academic Editor: Yiping Qiu

Copyright (C) 2015 Irwana Nainggolan et al. This is an open access article distributed under the Creative Commons Attribution License, which permits unrestricted use, distribution, and reproduction in any medium, provided the original work is properly cited.

Blend of chitosan and spinach extract has been successfully prepared using acetic acid as a solvent medium to produce chitosanspinach films. The conductivity measurements showed that chitosan-spinach films for all ratios of $95: 5,90: 10,85: 15$, and $80: 20$ had better conductivity than the chitosan film. The optical band gap reduced with the addition of the spinach extract into chitosan. Chitosan-spinach film with the ratio of $85: 15$ gave the best electrical properties in this work with the conductivity of $3.41 \times 10^{-6} \mathrm{~S} / \mathrm{m}$ and optical band gap of $2.839 \mathrm{eV}$. SEM-EDX spectra showed the existence of potassium, phosphorus, sulphur, iron, and oxygen in chitosan-spinach films. AFM image showed that the surface morphology of the films became rougher as the spinach incorporated into chitosan. The minerals which exist in spinach extract play a role in enhancing electrical properties of chitosan film.

\section{Introduction}

Chitosan, a linear $\beta$-linked polysaccharide, has long been marked as one of the most promising biopolymers. This biopolymer exhibits excellent characteristics including good chemical inertness, high mechanical strength, biodegradability, biocompatibility, high-quality film forming properties, and low cost [1]. Chitosan has been widely studied in various fields which include sensors, biomedical, food processing industries, and more. The broad application of chitosan biopolymer becomes one of the main reasons for the intensive investigation and development of these materials [1-4]. Chitosan is a unique material that is well suited for biological microdevices due to its ability to be selectivity deposited and its high density of amine groups, which provide active bonding sites [5], and it has the ability to retain its natural properties even after being processed into film [6]. However, the chitosan itself has a low conductivity value which limits its electronic applications. Therefore, composites or blends have been attempted by incorporating a conducting material into chitosan to combine the good process ability of the chitosan matrix and electrical conductivity of the conductive materials [1].

The chitosan-spinach films were expected to have better conductivity than the chitosan film because spinach contains minerals such as potassium, phosphorus, and iron (ferredoxin) [7]. Potassium (K) plays a critical role in adjusting the electronic properties of conductive materials [8]. Phosphorus (P) has been mostly used for doping. It has been reported that there is a proportionality relation between the conductivity and the doping concentration of phosphorus [9]. Spinach also contains ferredoxin which was represented as $[2 \mathrm{Fe}-2 \mathrm{~S}]^{2+}$. Ferredoxin is iron-sulfur proteins that function as electron carriers in many metabolic processes. The Fe (III) ions in $[2 \mathrm{Fe}-2 \mathrm{~S}]^{2+}$ are bridged by two sulfides and the tetrahedral coordination of each iron completed by cysteine residues. One electron reduction of the $[2 \mathrm{Fe}-2 \mathrm{~S}]^{2+}$ cluster occurs at one of the iron atoms to give the reduced $[2 \mathrm{Fe}-2 \mathrm{~S}]^{2+}$ cluster. In the oxidized state, both iron atoms are in a similar chemical state, which appears from the chemical shift and quadrupole splitting to be high-spin $\mathrm{Fe}^{3+}$. In the reduced state 
the iron atoms are different and the molecule appears to contain one high-spin $\mathrm{Fe}^{2+}$ and one high-spin $\mathrm{Fe}^{3+}[10]$. It was believed that the incorporation of spinach into chitosan matrix is able to improve the electrical properties of chitosan films by reducing the band gap of the films since the amine group in chitosan has the ability to bind cationic and anionic forms of noble and transition metal ions [11]. As far as we know, there is no reported study on the electrical conductivity, optical band gap, and microstructure of chitosanspinach films. Therefore, the success of using the spinach to improve the chitosan film characteristics in this study has made spinach able to function as a novel conductive additive with several advantages including being nontoxic, environmentally friendly, reproducible resource, abundant in nature, and cheap.

In this study, chitosan-spinach solution was prepared and coated on the glass substrate by spin coating. Chitosanspinach films were fabricated to study the conductivity, band gap energy, and microstructure of the films. Twopoint probe method was used to test the conductivity and UV-visible spectrometer was utilized to determine the band gap energy, while Fourier transform infrared spectroscopy (FTIR), scanning electron microscopy (SEM), and atomic force microscopy (AFM) were employed to characterize the prepared films.

\section{Experimental}

2.1. Materials. Chitosan from crab shell (degree of deacetylation $75-85 \%$, medium molecular weight) and methanol with purity of $99.98 \%$ were purchased from Sigma Aldrich Ltd. Meanwhile, acetic acid with purity of $99 \%$ purchased from Merck was used in this research. Red spinach was chosen as a biomaterial to be blended with chitosan. The red spinach was cleaned, cut, dried, and squeezed for spinach preparation purpose. Then, methanol, acetic acid, and distilled water were used for spinach extraction.

2.2. Preparation of Chitosan-Spinach Films. A solution gel of 1.75 wt.\% chitosan was prepared by dissolving chitosan into $2 \%$ acetic acid solution with rotation speed of $300 \mathrm{rpm}$ for $24 \mathrm{~h}$. After being cleaned, cut, dried, and squeezed, red spinach juice was poured into the mixture solution of methanol, acetic acid, and deionised water with the ratio $10: 4: 1: 5$ followed by magnetic stirring with rotation speed of $350 \mathrm{rpm}$ for $1 \mathrm{~h}$. Then, the chitosan solution was mixed with spinach extract and stirred for $2 \mathrm{~h}$. There are five distinct concentration solutions which were prepared using chitosan and spinach extract. One solution was made of pure chitosan as control, while the other four solutions were blends of chitosan and spinach extract with the spinach extract to chitosan ratios of $5 / 95,10 / 90,15 / 85$, and $20 / 80$, respectively. The chitosan and chitosan-spinach films were fabricated by using spin coating technique. In this work, rotation speed of $100 \mathrm{rpm}$ and spin time of 30 seconds were used to coat the chitosan and chitosan-spinach films on the glass substrate. Finally the films were annealed at $105^{\circ} \mathrm{C}$ to remove the excessive water molecules in the films.
2.3. Characterizations. There were several instruments that have been used in this research. Spin coater (WS-650 Mz23 NPP Laurell) was used to coat the chitosan and chitosanspinach solution onto the glass substrate. Vacuum oven was used for annealing purpose. Meanwhile the thickness of the films was measured using 3D-Profiler (Pemtron Hawk 3D). FTIR spectra measurements were conducted by a Perkin Elmer RX1 FTIR spectrometer. The surface morphology of chitosan and chitosan-spinach films was examined by using a Jeol JSM-6460LA scanning electron microscopy (SEM) at an accelerating voltage of $5 \mathrm{kV}$. The surface roughness of the films was investigated by atomic force microscopy (AFM) (Nanoscope IV/Multimode, Digital Instruments) equipped with a $100 \mu \mathrm{m}$ scanner operated in tapping mode. Conductivity of the chitosan and chitosan-spinach films was determined using the two-point probe method. The output current $(I)$ was measured for different input voltage $(V)$ ranging from $0 \mathrm{~V}$ to $20 \mathrm{~V}$ with the increment of $1 \mathrm{~V}$. The resistance $(R)$ and the conductance $(G)$ were obtained by using Ohm's Law [12]:

$$
\begin{gathered}
R=\frac{\Delta V}{\Delta I}, \\
G=\frac{1}{R} .
\end{gathered}
$$

Thus, the resistivity of the films was calculated by using

$$
\rho=R \times \frac{a}{t},
$$

where $\rho$ is the resistivity $(\Omega \cdot \mathrm{m})$ of the film, $R$ is the resistance of the film $(\Omega), a$ is the surface area of the film $\left(\mathrm{m}^{2}\right)$, and $t$ is the thickness of the film (m). Finally, after the value of the resistivity is obtained, the conductivity of the sample can be calculated using (3) where $\sigma$ is the conductivity:

$$
\sigma=\frac{1}{\rho} .
$$

The optical band gap was studied using UV-Vis spectrometer (Perkin Elmer UV-Vis spectrometer Lambda 35). Generally, the band gap energy $(\mathrm{Eg})$ in the semiconductor is determined by the Tauc equation [12] as described in

$$
[\alpha h v]^{2 / n}=K(h v-\mathrm{Eg}),
$$

where $n$ represent the nature of transition, $K$ is constant, and $h v$ is the energy of photon. Meanwhile, the energy of photon can be calculated using

$$
h v=\frac{h c}{\lambda},
$$

where $h$ is the plank constant $\left(6.626 \times 10^{-34} \mathrm{~m}^{2} \mathrm{~kg} / \mathrm{s}\right), c$ is the speed of light $\left(3 \times 10^{8} \mathrm{~m} / \mathrm{s}\right)$, and $\lambda$ is the wavelength $(\mathrm{m})$.

The absorption coefficient $\alpha(v)$ at various wavelength was calculated from absorbance $(A)$ and thickness $(t)$ of the sample using

$$
\alpha(v)=\frac{2.303 \times A(v)}{t} .
$$




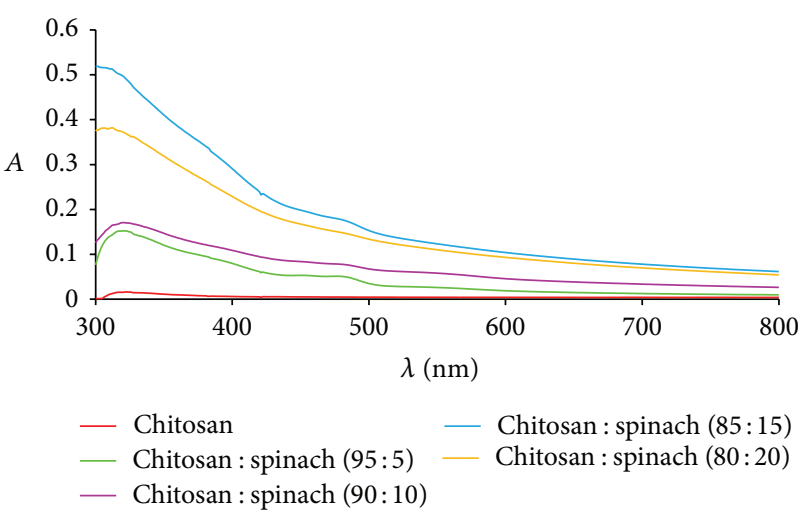

FIGURE 1: UV-Vis spectra of chitosan and chitosan-spinach blend films.

\section{Results and Discussion}

3.1. Optical Band Gap and Conductivity of Chitosan-Spinach Films. Figure 1 illustrates the UV-Vis spectra of chitosan film and chitosan-spinach film. The lower wavelength band is associated with the $\pi \pi^{*}$ transition of the conjugated ring systems $[1,13]$. Basically, the interaction is said to be strong if the wavelength is lower [13]. In this work, the absorptions occurred at the band with lower wavelength ranging from $350 \mathrm{~nm}$ to $300 \mathrm{~nm}$ that indicated there was a strong interaction between chitosan and spinach. It was found that the absorption $(A)$ of the film increased with increasing spinach content. However, the absorption decreased with the addition of $20 \%$ of spinach in chitosan. This result is in line with the data of SEM-EDX that, in general, the minerals content in spinach started to decrease when $20 \%$ of spinach is blended with the chitosan. It is because, at that concentration, the minerals have tendency to agglomerate and hence increase the particle-particle interaction of minerals. The agglomeration of the film is the factor that contributes to increment in band gap energy (reduction on the absorption) [11]. Thus, it can be concluded that the threshold or the optimum ratio of chitosan and spinach which shows the strongest interaction is $85: 15$. The absorption value $(A)$ was used to calculate the optical band gap energy using Tauc equation (4).

Table 1 shows electrical conductivity values of chitosan film and chitosan-spinach blend film. In general, the chitosan-spinach films have higher conductivity than chitosan film. The chitosan-spinach film with the ratio $15: 85$ has the highest conductivity of $3.41 \times 10^{-6} \mathrm{~S} / \mathrm{m}$. However, the conductivity value reduced to $3.25 \times 10^{-6} \mathrm{~S} / \mathrm{m}$ when $20 \%$ of spinach was blended with the chitosan due to agglomeration. The band gap energy became smaller prior to addition of spinach into chitosan as shown in Table 1. The chitosanspinach film with the ratio $15: 85$ has the smallest band gap energy which is $2.839 \mathrm{eV}$. However, the band gap energy seems to be increased to $3.807 \mathrm{eV}$ when $20 \%$ of spinach was incorporated into chitosan. Thus it can be concluded that the optimum ratio of spinach that can be incorporated into chitosan is $15 \%$.

The changes in the electrical properties of chitosanspinach films are attributed to the electron movement
TABLE 1: Thickness, conductivity, and band gap energy of chitosan and chitosan-spinach blend films.

\begin{tabular}{lccc}
\hline $\begin{array}{l}\text { Chitosan : spinach } \\
\text { ratio }\end{array}$ & $\begin{array}{c}\text { Thickness } \\
(\mu \mathrm{m})\end{array}$ & $\begin{array}{c}\text { Conductivity } \\
(\mathrm{S} / \mathrm{m})\end{array}$ & $\begin{array}{c}\text { Band gap } \\
(\mathrm{eV})\end{array}$ \\
\hline $100: 0$ & 48.954 & $4.2 \times 10^{-7}$ & 4.133 \\
$95: 5$ & 48.821 & $1.76 \times 10^{-6}$ & 4.125 \\
$90: 10$ & 49.045 & $2.54 \times 10^{-6}$ & 4.118 \\
$85: 15$ & 48.630 & $3.41 \times 10^{-6}$ & 2.839 \\
$80: 20$ & 49.023 & $3.25 \times 10^{-6}$ & 3.807 \\
\hline
\end{tabular}

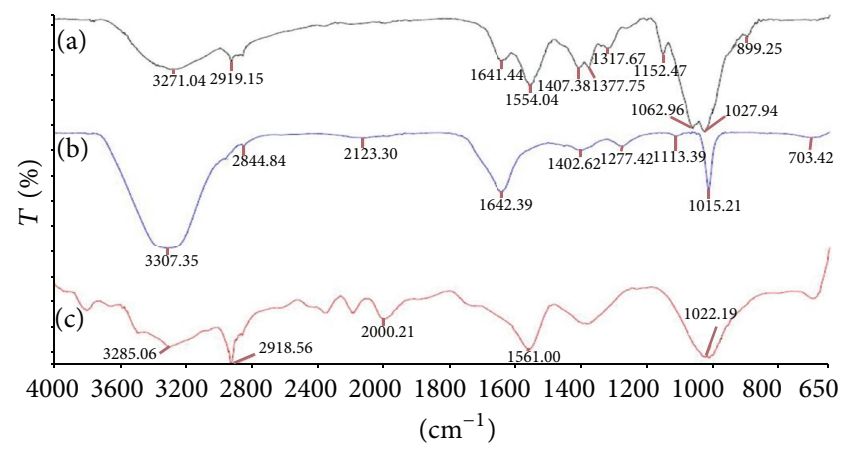

FIGURE 2: Infrared spectra of (a) chitosan film, (b) spinach extract, and (c) chitosan-spinach blend film.

within the chitosan-spinach films. Chitosan has amino $\left(\mathrm{NH}_{2}\right)$ and hydroxyl $(\mathrm{OH})$ groups. These functional groups provide active bonding sites to interact with the metals complexes [14]. SEM-EDX micrographs of chitosan-spinach films (Figure 3) show the existence of potassium, phosphorus, iron, sulphur, and oxygen in these films. The existence of potassium, phosphorus, and ferredoxin contributes to the enhancement in output voltage or current because the ions create extra free electrons and pathway for electron transfer. The potassium ion is necessary for redox reaction of electron carrier. Potassium ion also has a rapid electron transfer rate and, as a dopant, it has a tendency to enhance the conductivity of the host materials [15]. As a dopant, phosphorus can increase surface electronic density and enhance the ability of adsorbed oxygen. Phosphorus is able to reduce the resistance of host materials [16]. One electron reduction of the ferredoxin cluster occurs at one of the iron atoms to give the reduced $[2 \mathrm{Fe}-2 \mathrm{~S}]^{+}$. The reduced electrons then become the free electrons that move randomly in chitosan-spinach film under the certain supplied voltage. Therefore, the higher percentage of spinach extract in the blend films caused the presence of free electrons much more and, in turn, enhanced the conductivity of the blend films.

3.2. Fourier Transform Infrared Spectroscopy (FTIR). The FTIR spectrum of the chitosan film is shown in Figure 2(a). In the spectrum of chitosan, the band at $3271 \mathrm{~cm}^{-1}$ is due to $-\mathrm{OH}$ vibration [17]. This band is quite broad and has covered characteristic $-\mathrm{NH}$ band for chitosan at $1641 \mathrm{~cm}^{-1}$ and band at $1554 \mathrm{~cm}^{-1}$ belonging to $-\mathrm{NH}_{2}$ bending. The band occurring at $1377 \mathrm{~cm}^{-1}$ is ascribed to the $\mathrm{C}-\mathrm{OH}$ vibration of the alcohol 


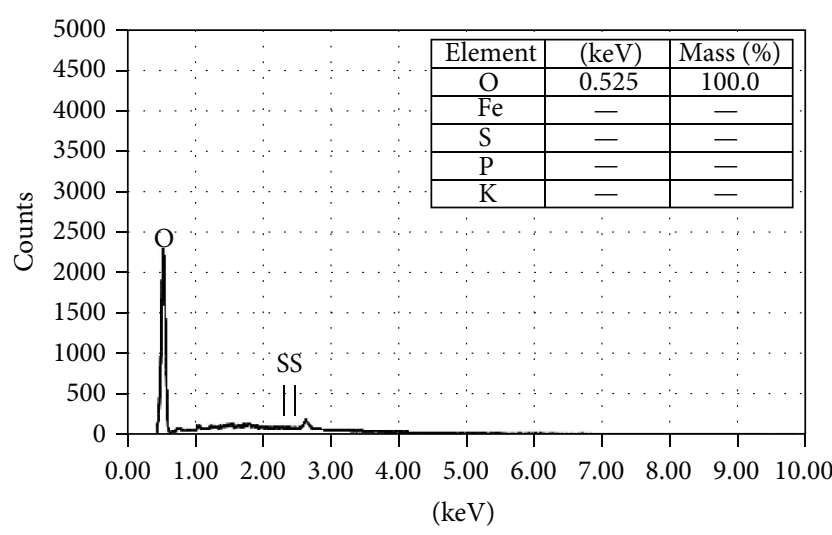

(a)

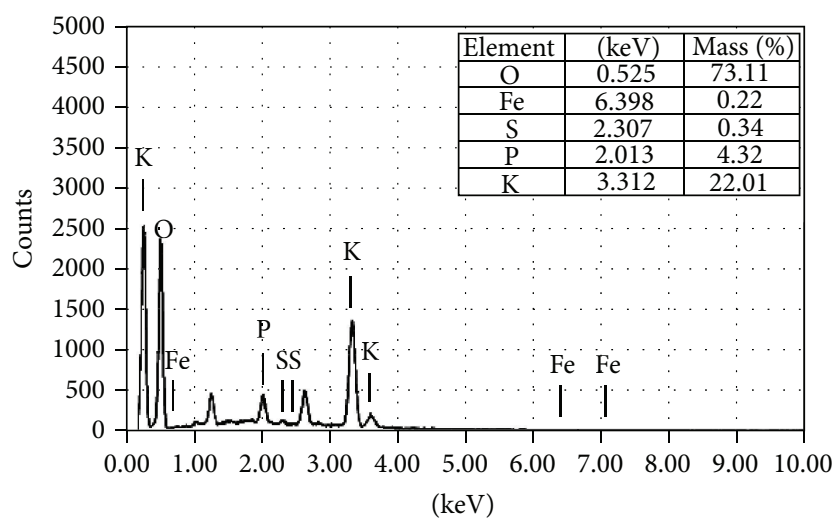

(c)

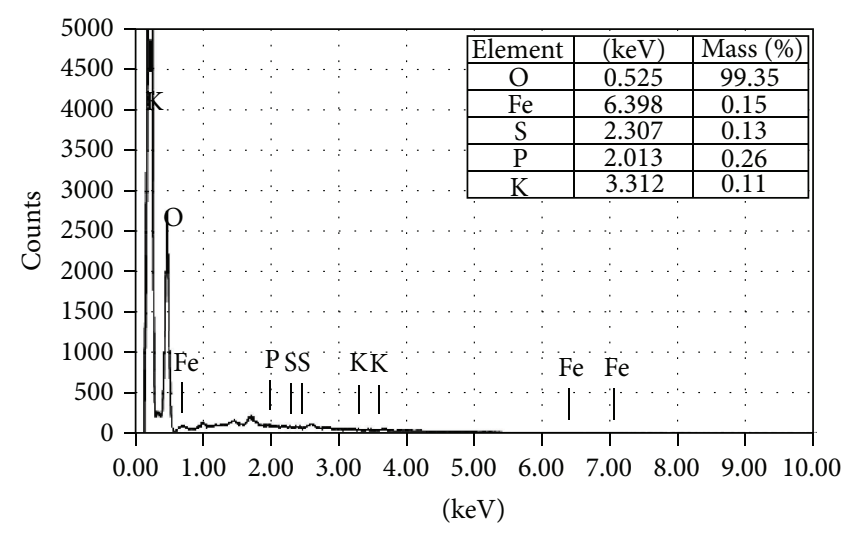

(b)

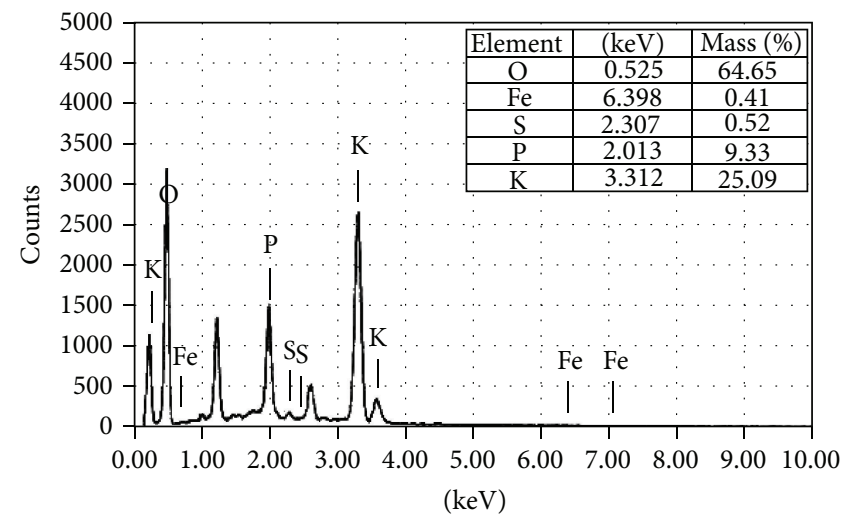

(d)

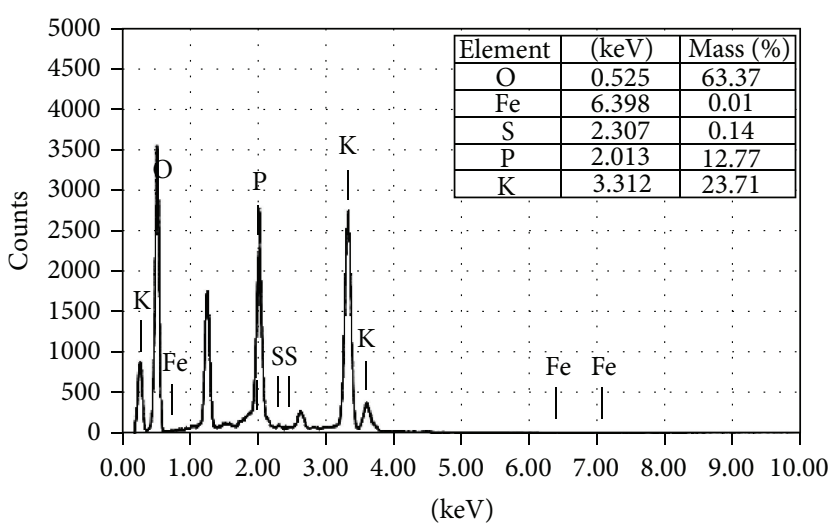

(e)

FIGURE 3: SEM (EDX) micrographs of (a) chitosan film, (b) chitosan-spinach blend film (95:5), (c) chitosan-spinach blend film (90:10), (d) chitosan-spinach blend film $(85: 15)$, and (e) chitosan-spinach blend film $(80: 20)$.

groups in the chitosan and the band around $2919 \mathrm{~cm}^{-1}$ is ascribed to the $\mathrm{C}-\mathrm{H}$ stretching mode in the chitosan [18]. The absorption band at $1152 \mathrm{~cm}^{-1}$ due to antisymmetric stretching of $\mathrm{C}-\mathrm{O}-\mathrm{C}$ bridge and the $1062 \mathrm{~cm}^{-1}$ skeletal vibration involving the $\mathrm{C}-\mathrm{O}$ stretching is characteristic of its saccharide structure [19].

The FTIR spectra of spinach can be seen in Figure 2(b). In the spectrum of spinach, the iron sulphides do not provide clear absorption bands at lower wavenumber in the infrared spectrum. The presence of asymmetric stretching of carboxylate $(\mathrm{C}=\mathrm{O})_{2}$ at $1642 \mathrm{~cm}^{-1}$ is typical of amino acid, a weak band at $1402 \mathrm{~cm}^{-1}$ characteristic of ammonium ion $\mathrm{NH}_{4}{ }^{+}$, and band at $1113 \mathrm{~cm}^{-1}$ indicating the presence of sulfate. The band occurring at $2123 \mathrm{~cm}^{-1}$ is ascribed to the existence of ferredoxin [Fe-S] [20]. The band occurring at $3307 \mathrm{~cm}^{-1}$ is due to $-\mathrm{OH}$ vibration and the band around $2844 \mathrm{~cm}^{-1}$ is ascribed to the $\mathrm{C}-\mathrm{H}$ stretching mode in the spinach. 
It can be seen from the FTIR spectra (Figure 2(c)) that the blend film has the characteristic bands of both chitosan and spinach ferredoxin. The $3285 \mathrm{~cm}^{-1}, 2918 \mathrm{~cm}^{-1}, 1561 \mathrm{~cm}^{-1}$, and $1022 \mathrm{~cm}^{-1}$ bands are characteristics of the $-\mathrm{OH}$ vibration, $\mathrm{C}-$ $\mathrm{H}$ stretching, $-\mathrm{NH}_{2}$ bending, and skeletal vibration involving the $\mathrm{C}-\mathrm{O}$ stretching present in chitosan. The spectrum of the $\mathrm{NH}_{2}$ group overlapped with the $\mathrm{O}-\mathrm{H}$ group was shifted from $3271 \mathrm{~cm}^{-1}$ (chitosan film) to $3285 \mathrm{~cm}^{-1}$ (chitosanspinach film). Besides that, the free amine group observed at $1641 \mathrm{~cm}^{-1}$ (chitosan film) disappears. These two phenomena indicate that $\mathrm{NH}_{2}$ and $\mathrm{OH}$ groups take part in complex formation with ferredoxin $[21,22]$. The band occurring at $2000 \mathrm{~cm}^{-1}$ is ascribed to the existence of ferredoxin [Fe-S] in the blend. The Fe-S stretching is seen around $2123 \mathrm{~cm}^{-1}$ in the spectra of spinach. However, the band has shifted to lower wavenumber in the blend, that is, $2000 \mathrm{~cm}^{-1}$. This result indicates larger interaction between spinach ferredoxin and chitosan. Theoretically, chitosan has a free amine group in its molecular structure. On the other hand, ferredoxin which is linked with sulfur consists of $\mathrm{Fe}^{3+}$ where it can reduce to $\mathrm{Fe}^{2+}$ by interacting with the free amine group in chitosan [23]. The complex formation induces the increment of conductivity since it creates an extra pathway for the electrons to flow, which is consistent with data of conductivity and band gap as depicted in Table 1.

\subsection{Scanning Electron Microscope (SEM). The SEM-EDX} micrographs obtained from chitosan film and chitosanspinach film are presented in Figure 3. The SEM-EDX micrograph of the chitosan film (Figure 3(a)) shows the existence of oxygen whereas SEM-EDX micrographs of chitosan-spinach films (Figures 3(b)-3(e)) show the existence of potassium, phosphorus, iron, sulphur, and oxygen. The potassium, phosphorus, iron, and sulphur contents increase as the amount of spinach increases as shown in Figures 3(b), 3(c), and 3(d). The mass of potassium is $0.11 \%, 22.01 \%$, and $25.09 \%$ for spinach contents of $5 \%, 10 \%$, and $15 \%$, respectively; however the mass of potassium decreased to 23.71 when $20 \%$ of spinach content was blended with the chitosan. The mass of phosphorus is $0.26 \%, 4.32 \%, 9.33 \%$, and $12.77 \%$ for spinach content of $5 \%, 10 \%, 15 \%$, and $20 \%$, respectively. The iron mass increment is almost the same with the potassium; the mass increased up to $15 \%$ and decreased when $20 \%$ of spinach content was blended with the chitosan. Meanwhile, the sulphur content also increased as the spinach content increased. The amount of sulphur in percentage is $0.13 \%$, $0.34 \%$, and $0.52 \%$ for spinach content of $5 \%, 10 \%$, and $15 \%$, respectively. However the amount of this component reduced at spinach content of $20 \%$ (Figure 3(e)) where the sulphur content drops to $0.14 \%$. In general, the minerals content started to decrease when $20 \%$ of spinach is blended with the chitosan because, at that concentration, the minerals have tendency to agglomerate and hence increase the particleparticle interaction of minerals as we can see in Figure 4(e).

Figure 4 describes the morphology of the chitosan film and chitosan-spinach blend film. It appears that morphology has some influence on the electrical conductivity of the films [1]. Chitosan as in Figure 4(a) shows a homogenous surface.
This result is consistent with the previous work which has been done before [17]. The presence of a nonhomogeneous structure in Figures 4(b), 4(c), 4(d), and 4(e) serves as an evidence for the interaction between chitosan and spinach extract which indicates that chitosan and metals content in spinach form complexes. The compact surface of the films affects the electrical properties of the films since the compact surface enhances the pathways for electron transfer. Besides that, the compact surface indicated that the films were well deposited onto the substrate. The strong bond of the films and substrate is very important to avoid swelling of the films; besides the suitable annealing temperature $\left(105^{\circ} \mathrm{C}\right)$ is important parameter to remove the water molecules which exist in the films and to make the films surface compact. The uneven surface of blend films is because the interaction between the chitosan and metals content in spinach forms complexes. There are no significant changes in the surface morphology when $5 \%$ of spinach was incorporated in chitosan (Figure 4(b)). The morphology of the film started to change via addition of $10 \%$ of spinach where it becomes rougher as shown in Figure 4(c). Figure 4(d) shows the chitosan and spinach extract form almost uniform surface when $15 \%$ of spinach was blended with chitosan. It indicates that spinach extract disperses well within the chitosan and they have good interaction. However, the chitosan-spinach film started to agglomerate when $20 \%$ spinach extract was blended with chitosan as shown in Figure 4(e). The agglomeration of the film is the factor that contributes to increment in band gap energy and reduction in the conductivity value [24]. Thus, it can be concluded that the optimum ratio of spinach that can be incorporated into chitosan is $15 \%$.

3.4. Atomic Force Microscope (AFM). The surfaces of the films were mapped by atomic force microscopy (AFM) with the aim of observing the differences in the film surface associated with the interaction between spinach extract and chitosan. The roughness of the films was determined by the value of RMS and Ra value from AFM data where higher RMS and $\mathrm{Ra}$ value indicate that the film surface is getting rougher [25]. Figure 5 shows 3D image of chitosan and chitosanspinach films. The chitosan film presents a flat homogeneous surface exhibiting a very low dispersion in the roughness profile which is $0.372 \mathrm{~nm}$. It is consistent with the result from previous work done by $\operatorname{Li}[26,27]$. It can be observed that the chitosan-spinach films display a rough surface in Figures 4(b), 4(c), 4(d), and 4(e). The roughness of the films increases with increasing spinach extract content as indicated by the RMS values starting from $1.413 \mathrm{~nm}, 4.848 \mathrm{~nm}, 12.980 \mathrm{~nm}$, and $36.250 \mathrm{~nm}$ for spinach extract content of $5 \%, 10 \%, 15 \%$, and $20 \%$, respectively, as listed in Table 2 . The roughness of the films can be explained through the difference between the minimum and maximum peaks on AFM image of the film surface. The axis in Figure 5 clearly illustrates that the height of peaks increases with the increasing of spinach extract concentration. This can be associated with the interaction between the chitosan and spinach extract which indicates that chitosan and metals content in spinach form complexes. 


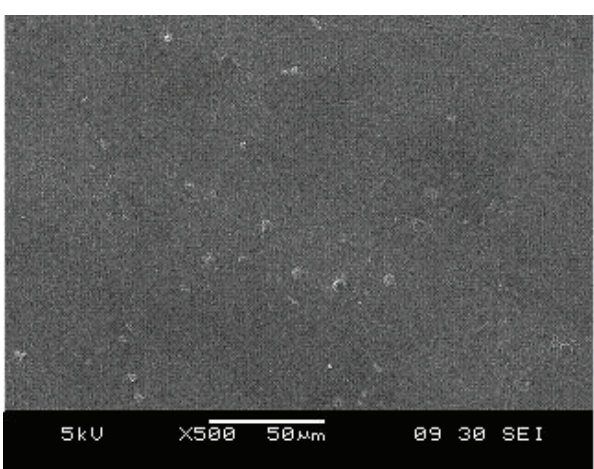

(a)

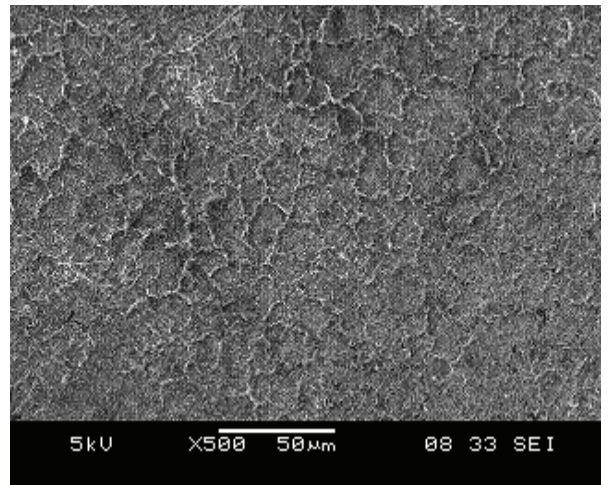

(c)

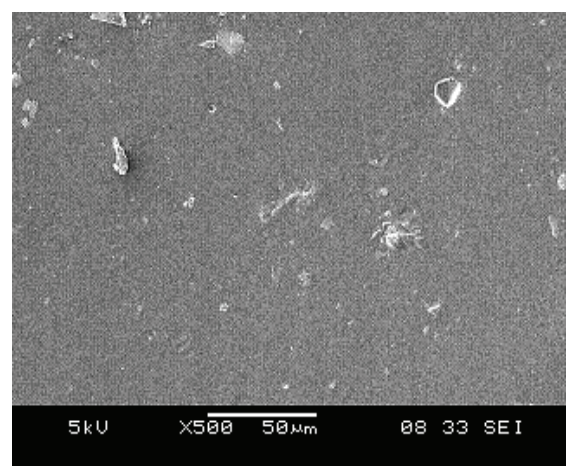

(b)

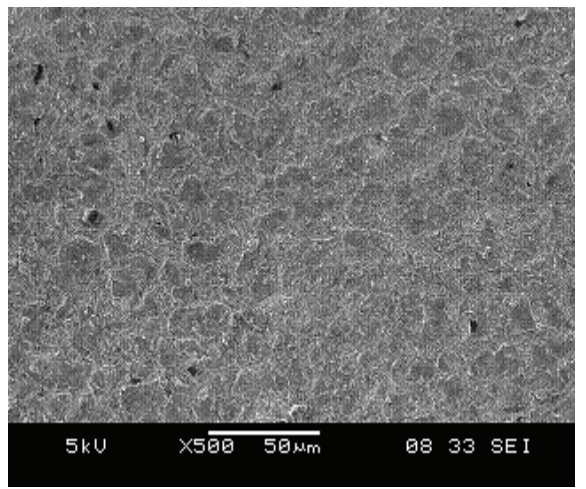

(d)

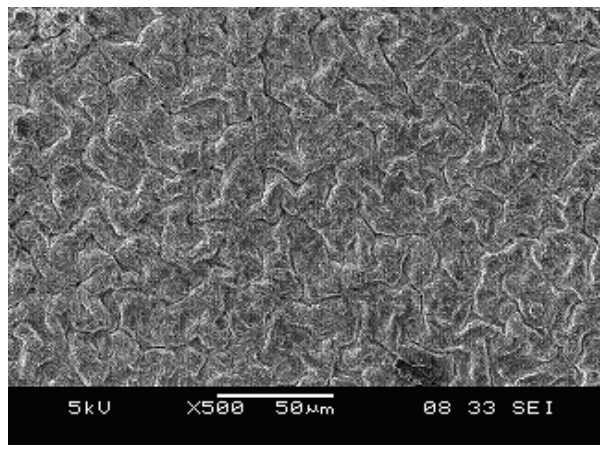

(e)

FIGURE 4: SEM images of (a) chitosan film, (b) chitosan-spinach blend film (95:5), (c) chitosan-spinach blend film (90:10), (d) chitosanspinach blend film (85:15), and (e) chitosan-spinach blend film (80:20).

TABLE 2: Surface analysis data of the chitosan film and chitosanspinach blend film.

\begin{tabular}{lccccc}
\hline Chitosan : spinach & $100: 0$ & $95: 5$ & $90: 10$ & $85: 15$ & $80: 20$ \\
\hline Rms (nm) & 0.372 & 1.413 & 4.848 & 12.980 & 36.250 \\
Ra (nm) & 0.235 & 1.022 & 3.747 & 10.200 & 20.391 \\
\hline
\end{tabular}

\section{Conclusion}

The chitosan film properties have been successfully improved by blending chitosan with spinach extract. The existence of potassium, phosphorus, and ferredoxin in spinach resulted in the optical band gap of chitosan-spinach films becoming narrower than chitosan film. As a result, the electrical conductivity of chitosan-spinach films was higher compared to chitosan film. Besides that, the presence of a nonhomogeneous structure served as an evidence for the interaction between chitosan and spinach which indicates that chitosan and metals content in spinach form complexes. Therefore, spinach has been proven as a new effective conductive additive for the purpose of improving the electrical properties of chitosan film wherein the chitosan-spinach film with the ratio of $85: 15$ has been found as the best ratio to fabricate the blend films. 


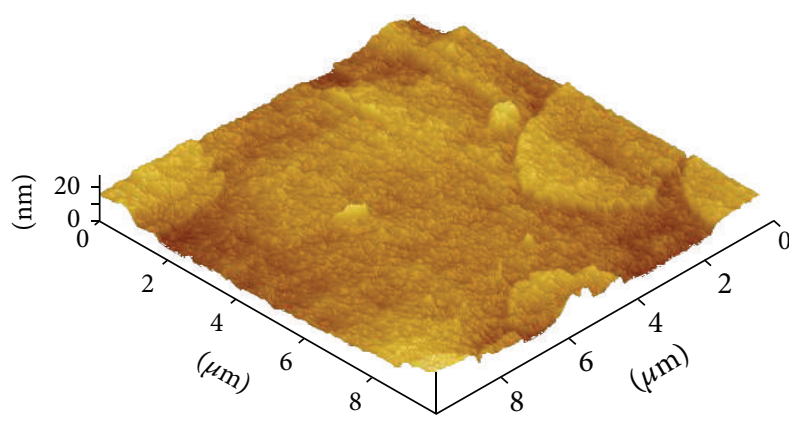

(a)

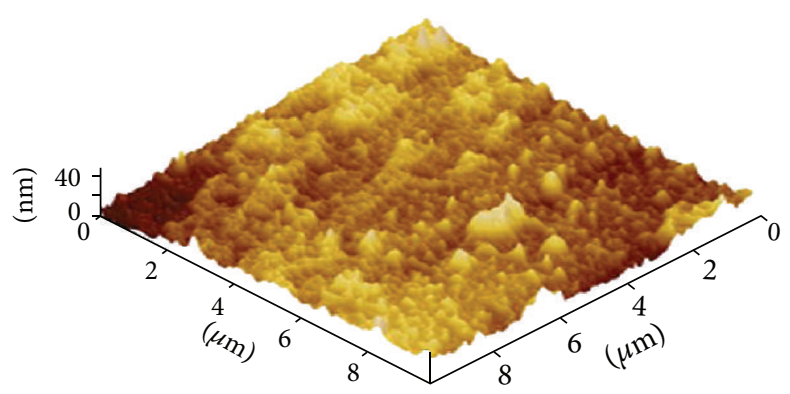

(c)

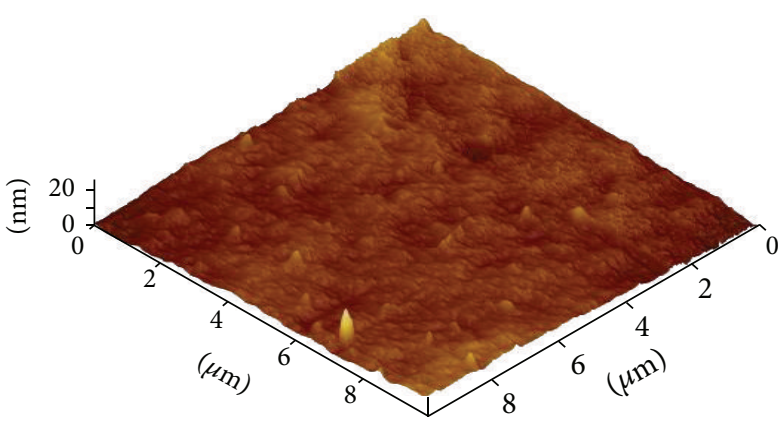

(b)

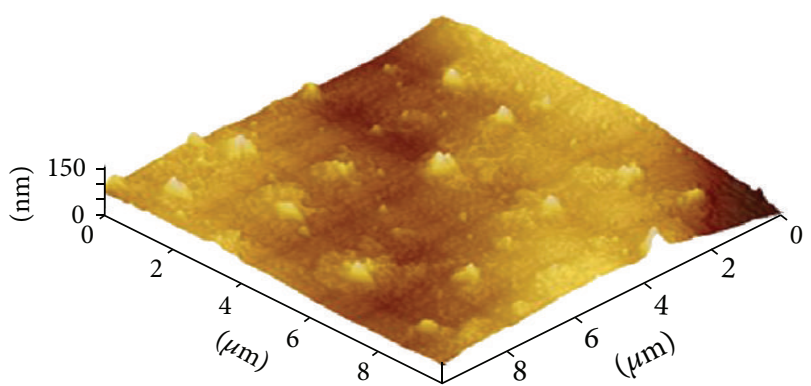

(d)

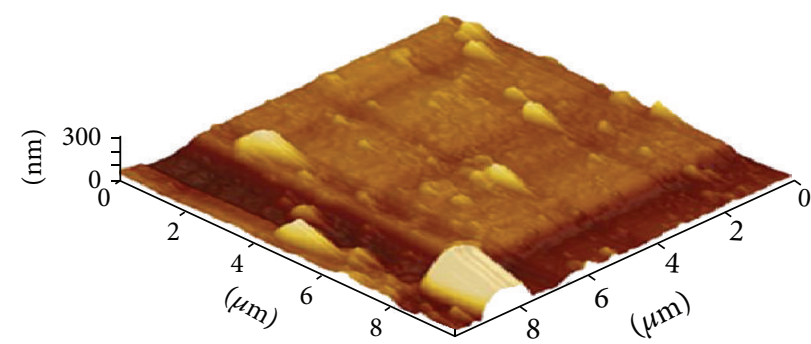

(e)

Figure 5: AFM (3D) images of (a) chitosan film, (b) chitosan-spinach blend film (95:5), (c) chitosan-spinach blend film (90:10), (d) chitosanspinach blend film $(85: 15)$, and (e) chitosan-spinach blend film $(80: 20)$.

\section{Conflict of Interests}

The authors declare that there is no conflict of interests regarding the publication of this paper.

\section{Acknowledgments}

This work was financially supported by FRGS research grant (Project no. 9003-00436). The authors thank School of Materials Engineering, UniMAP, for other supports.

\section{References}

[1] A. G. Yavuz, A. Uygun, and V. R. Bhethanabotla, "Substituted polyaniline/chitosan composites: synthesis and characterization," Carbohydrate Polymers, vol. 75, no. 3, pp. 448-453, 2009.

[2] N. K. Mathur and C. K. Narang, "Chitin and chitosan, versatile polysaccharides from marine animals," Journal of Chemical Education, vol. 67, no. 11, pp. 938-942, 1990.

[3] M. N. V. R. Kumar, "A review of chitin and chitosan applications," Reactive and Functional Polymers, vol. 46, no. 1, pp. 1-27, 2000.
[4] C. Stefanescu, W. H. Daly, and I. I. Negulescu, "Biocomposite films prepared from ionic liquid solutions of chitosan and cellulose," Carbohydrate Polymers, vol. 87, no. 1, pp. 435-443, 2012.

[5] P. Dykstra, J. Hao, S. T. Koev, G. F. Payne, L. Yu, and R. Ghodssi, "An optical MEMS sensor utilizing a chitosan film for catechol detection," Sensors and Actuators, B: Chemical, vol. 138, no. 1, pp. 64-70, 2009.

[6] D. Du, J. Ding, J. Cai, and A. Zhang, "One-step electrochemically deposited interface of chitosan-gold nanoparticles for acetylcholinesterase biosensor design," Journal of Electroanalytical Chemistry, vol. 605, no. 1, pp. 53-60, 2007.

[7] S. Smoleń and W. Sady, "Influence of iodine form and application method on the effectiveness of iodine biofortification, nitrogen metabolism as well as the content of mineral nutrients and heavy metals in spinach plants (Spinacia oleracea L.)," Scientia Horticulturae, vol. 143, pp. 176-183, 2012.

[8] X.-R. Li, J. Liu, F.-Y. Kong, X.-C. Liu, J.-J. Xu, and H.-Y. Chen, "Potassium-doped graphene for simultaneous determination of nitrite and sulfite in polluted water," Electrochemistry Communications, vol. 20, no. 1, pp. 109-112, 2012. 
[9] A. Bakry and A. M. El-Naggar, "Correlation between phosphorus concentration and opto-electrical properties of doped aSi:H films," Optik, vol. 124, no. 24, pp. 6501-6505, 2013.

[10] K. K. Rao, R. Cammack, D. O. Hall, and C. E. Johnson, "Mössbauer effect in Scenedesmus and spinach ferredoxins. The mechanism of electron transfer in plant-type iron-sulphur proteins," Biochemical Journal, vol. 122, no. 3, pp. 257-265, 1971.

[11] A. Mironenko, E. Modin, A. Sergeev, S. Voznesenskiy, and S. Bratskaya, "Fabrication and optical properties of chitosan/Ag nanoparticles thin film composites," Chemical Engineering Journal, vol. 244, pp. 457-463, 2014.

[12] M. M. Abdi, H. N. M. E. Mahmud, L. C. Abdullah, A. Kassim, M. Z. A. Rahman, and J. L. Y. Chyi, "Optical band gap and conductivity measurements of polypyrrole-chitosan composite thin films," Chinese Journal of Polymer Science, vol. 30, no. 1, pp. 93-100, 2012.

[13] P. Kannusamy and T. Sivalingam, "Chitosan- $\mathrm{ZnO} /$ polyaniline hybrid composites: polymerization of aniline with chitosan$\mathrm{ZnO}$ for better thermal and electrical property," Polymer Degradation and Stability, vol. 98, no. 5, pp. 988-996, 2013.

[14] X. H. Wang, Y. Du, and H. Liu, "Preparation, characterization and antimicrobial activity of chitosan-Zn complex," Carbohydrate Polymers, vol. 56, no. 1, pp. 21-26, 2004.

[15] Y. Mishima, J. Motonaka, K. Maruyama, and S. Ikeda, "Determination of hydrogen peroxide using a potassium hexacyanoferrate(III) modified titanium dioxide electrode," Analytica Chimica Acta, vol. 358, no. 3, pp. 291-296, 1998.

[16] Z. Han, J. Wang, L. Liao, H. Pan, S. Shen, and J. Chen, "Phosphorus doped $\mathrm{TiO}_{2}$ as oxygen sensor with low operating temperature and sensing mechanism," Applied Surface Science, vol. 273, pp. 349-356, 2013.

[17] S. Yalçinkaya, C. Demetgül, M. Timur, and N. Çolak, "Electrochemical synthesis and characterization of polypyrrole/chitosan composite on platinum electrode: its electrochemical and thermal behaviors," Carbohydrate Polymers, vol. 79, no. 4, pp. 908-913, 2010.

[18] Y. A. Ismail, S. R. Shin, K. M. Shin et al., "Electrochemical actuation in chitosan/polyaniline microfibers for artificial muscles fabricated using an in situ polymerization," Sensors and Actuators, B: Chemical, vol. 129, no. 2, pp. 834-840, 2008.

[19] S. J. Kim, S. R. Shin, S. M. Lee, I. Y. Kim, and S. I. Kim, "Electromechanical properties of hydrogels based on chitosan and poly(hydroxyethyl methacrylate) in $\mathrm{NaCl}$ solution," Smart Materials and Structures, vol. 13, no. 5, pp. 1036-1039, 2004.

[20] M. R. M. Chaves, K. T. Valsaraj, R. D. DeLaune, R. P. Gambrell, and P. M. Buchler, "Modification of mackinawite with L-cysteine: synthesis, characterization, and implications to mercury immobilization in sediment," in Sediment Transport, chapter 16, University of Sao Paulo, Sao Paulo, Brazil, 2008.

[21] X. Wang, Y. Du, L. Fan, H. Liu, and Y. Hu, "Chitosan-metal complexes as antimicrobial agent: Synthesis, characterization and Structure-activity study," Polymer Bulletin, vol. 55, no. 1-2, pp. 105-113, 2005.

[22] H. T. Boey, W. L. Tan, N. H. H. A. Bakar, M. A. Bakar, and J. Ismail, "Formation and morphology of colloidal chitosanstabilized copper sulphides," Journal of Physical Science, vol. 18, no. 1, pp. 87-101, 2007.

[23] S. Gao, J. Fan, S. Sun et al., "Di/mono-nuclear iron(i)/(ii) complexes as functional models for the $2 \mathrm{Fe}_{2} \mathrm{~S}$ subunit and distal $\mathrm{Fe}$ moiety of the active site of [FeFe] hydrogenases: protonations, molecular structures and electrochemical properties," Dalton Transactions, vol. 41, no. 39, pp. 12064-12074, 2012.
[24] N. N. Mobarak, A. Ahmad, M. P. Abdullah, N. Ramli, and M. Y. A. Rahman, "Conductivity enhancement via chemical modification of chitosan based green polymer electrolyte," Electrochimica Acta, vol. 92, pp. 161-167, 2013.

[25] A. P. P. Praxedes, A. J. C. da Silva, R. C. da Silva et al., "Effects of UV irradiation on the wettability of chitosan films containing dansyl derivatives," Journal of Colloid and Interface Science, vol. 376, no. 1, pp. 255-261, 2012.

[26] J. Li, S. Zivanovic, P. M. Davidson, and K. Kit, "Production and characterization of thick, thin and ultra-thin chitosan/PEO films," Carbohydrate Polymers, vol. 83, no. 2, pp. 375-382, 2011.

[27] W. H. Nosal, D. W. Thompson, L. Yan, S. Sarkar, A. Subramanian, and J. A. Woollam, "Infrared optical properties and AFM of spin-cast chitosan films chemically modified with 1,2 Epoxy3-phenoxy-propane," Colloids and Surfaces B: Biointerfaces, vol. 46, no. 1, pp. 26-31, 2005. 

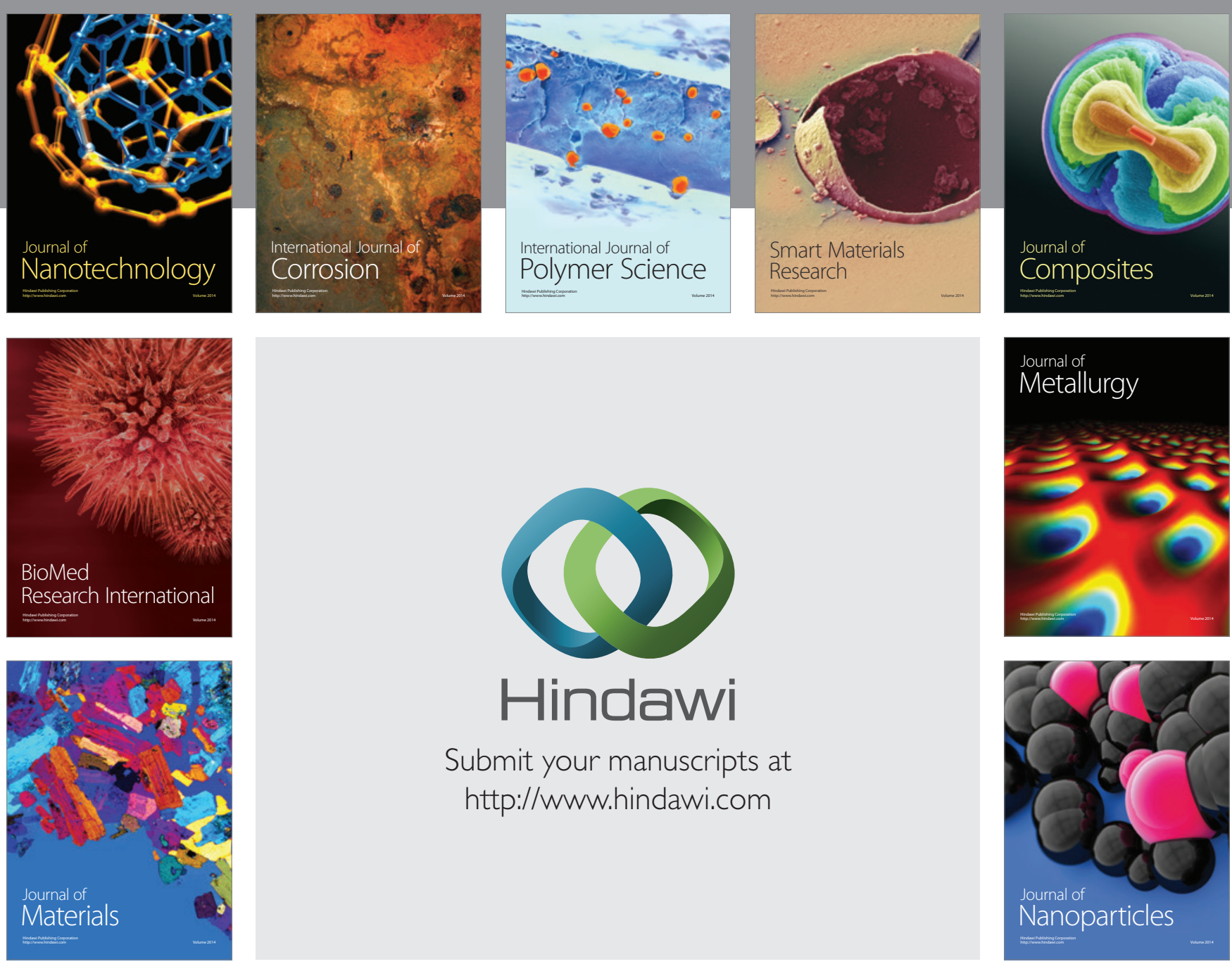

Submit your manuscripts at http://www.hindawi.com
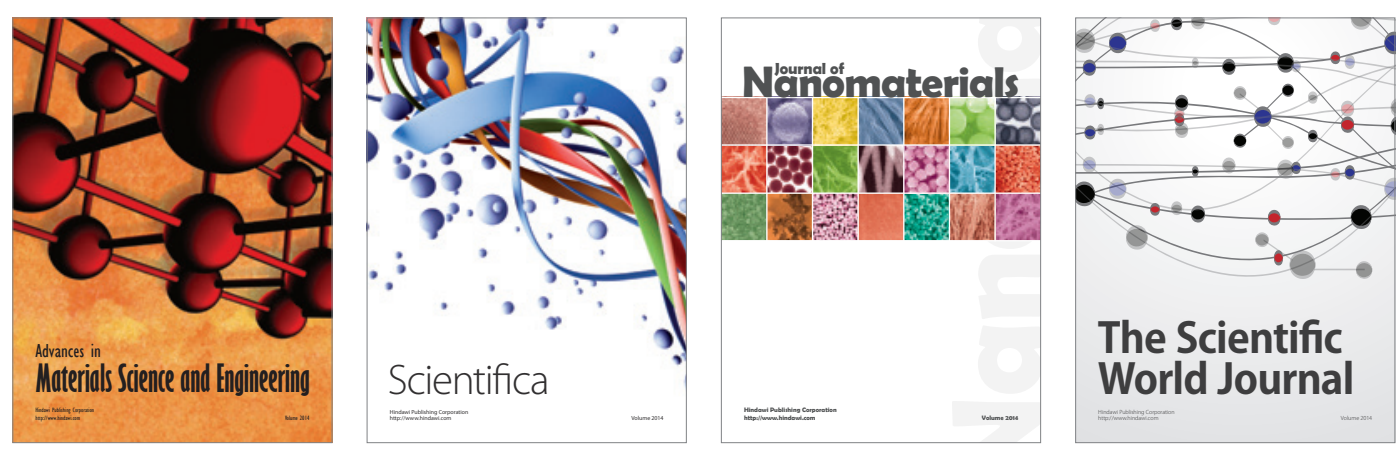

\section{The Scientific World Journal}
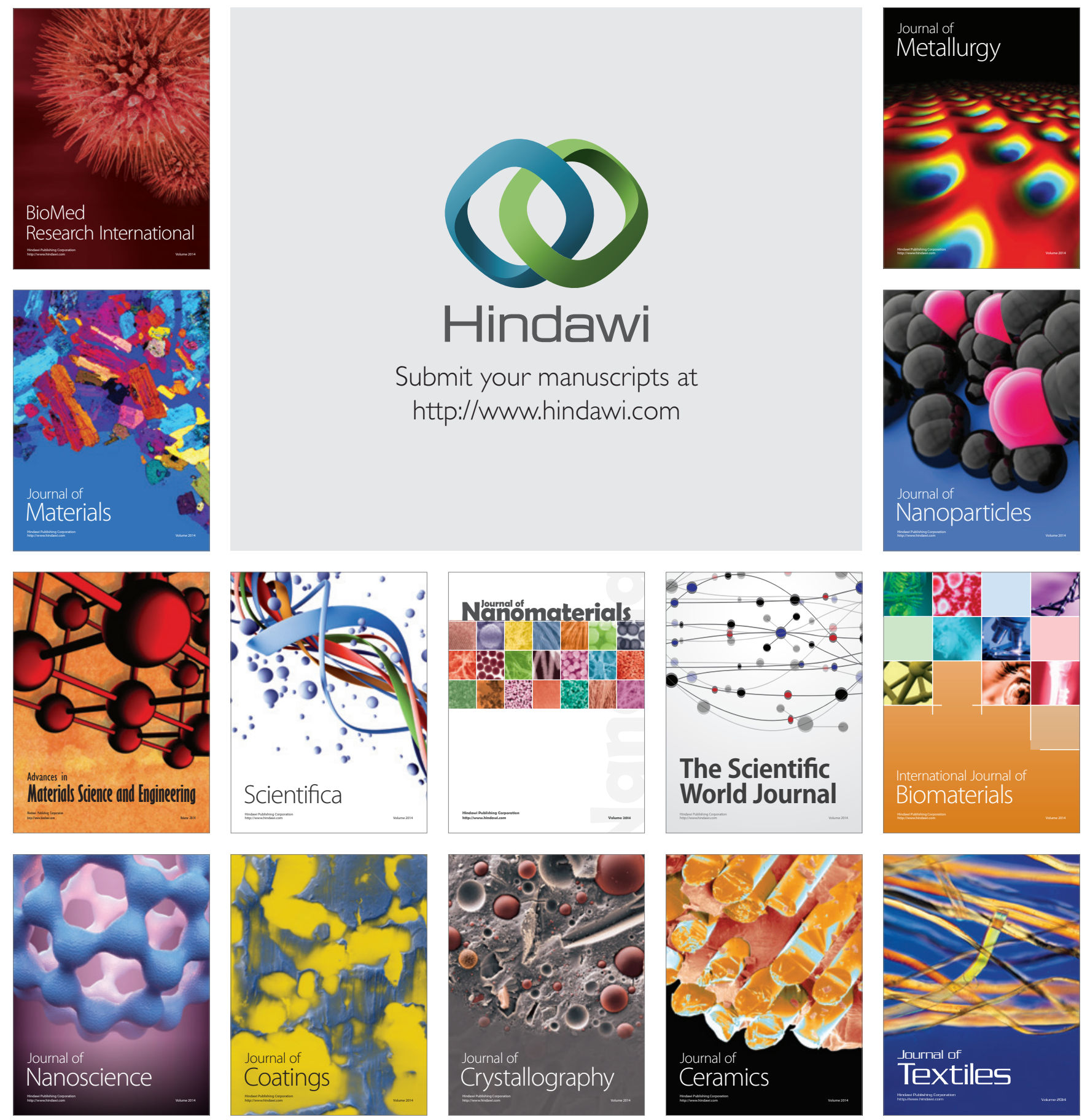